\title{
A META-MODEL FOR PRODUCT SERVICE SYSTEMS OF SYSTEMS
}

\author{
S. Fakhfakh ${ }^{1,2, \otimes}$, A. M. Hein ${ }^{1}$, M. Jankovic ${ }^{1}$ and Y. Chazal ${ }^{2}$ \\ ${ }^{1}$ CentraleSupélec, France, ${ }^{2}$ Groupe Renault, France \\ $\bigotimes$ sarra.fakhfakh@centralesupelec.fr
}

\begin{abstract}
A Product Service System of Systems (PSSoS) is a set of products, services, infrastructure, and a network where its constituent elements exhibit operational and managerial independence. As such, a PSSoS shows PSS characteristics of heterogeneity and evolvability and SoS characteristics of emergence and diversity. Neither existing PSS nor SoS development approaches fully address these characteristics. Thus, PSSoS development raises new challenges. In this paper, we propose a PSSoS meta-model that integrates PSS and SoS key concepts, to provide a basis for future PSSoS development methods.
\end{abstract}

Keywords: product-service systems (PSS), system of systems (SoS), modelling, complex systems

\section{Introduction}

To diversify its sources of value and remain competitive, the manufacturing industry sells services along with manufactured products, and as such, develops Product Service Systems (PSS). A PSS is a bundle of products, services, infrastructure, and supporting network (Mont, 2002). Thus, a PSS involves heterogeneous systems jointly capable of satisfying customer's needs. To successfully develop such a system, the manufacturing industry collaborates with other actors and shares the design, development, management, and operation of PSS constituent systems (Fakhfakh et al., 2019; Hein et al., 2018). For example, a large automotive company, an energy provider, and an infrastructure manager collaborate and jointly develop and operate PSSs (EV2G) (Chazal, 2018). This collaborative development of PSSs shows an increasing complexity of PSSs and a shift to developing Product Service Systems of Systems (PSSoSs). A PSSoS is defined by Hein et al. (2018) as a PSS showing characteristics of Systems of systems (SoSs), namely operational and managerial independence of the elements, emergent behaviour, etc (Maier, 1996). Hence, PSSoSs development raises new design challenges (Fakhfakh et al., 2019). Systems are heterogeneous and independent. Designing their interfaces, integrating them, and ensuring their interoperability is challenging. Independent and heterogeneous systems also have independent lifecycles with different time spans. This makes the design of a PSSoS even more difficult. Besides, the combination of actor collaboration alternatives, role allocation alternatives, and product, service, and PSS alternatives increases the difficulty of designing PSSoSs. Therefore, it is important to address these new challenges by integrating the characteristics of a PSSoS into an appropriate PSSoS design method. However, PSS and SoS have been studied separately in the literature (Fakhfakh et al., 2019). Studying both PSS design methods and SoS design methods, Hein et al. (2018) showed that:

- PSS design methods rarely consider the increasing complexity of PSSs. Thus, these methods do not address the managerial and operational independence of the PSS elements. Also, PSS 
publications mainly focus on the collaboration and the co-creation with the customer during the operation phase. They do not consider business partnerships in the design of combinations of products, services, and PSSs.

- SoS design methods deal with highly complex systems. However, the SoS literature rarely takes into account PSS aspects namely service characteristics and features of heterogeneity. Moreover, SoS literature focuses on organizational aspects, e.g. actors' role allocation.

This paper aims to first represent and describe PSSoS. We present a PSSoS conceptual model (i.e. a PSSoS meta-model). This PSSoS meta-model includes PSS and SoS key design concepts. Thus, the meta-model presents the data necessary for the description of PSSoSs. It also structures the links and rules between data elements.

The structure of the paper is as follows. In section 2, we describe the adopted research approach. In section 3, we review PSS and SoS modelling approaches to extract key concepts for PSSoS representation. In section 4, we discuss experts' feedback and illustrate the use of the PSSoS metamodel. We finally conclude and discuss future research avenues in section 5 .

\section{Research approach}

\subsection{Meta-modelling research approach}

This paper aims to build a representation of PSSoS key concepts by integrating PSS and SoS key concepts. Therefore, we propose a PSSoS meta-model that captures these concepts and their relationships. To build this meta-model, we followed a 3 steps method similar to the one used. The first step consists in reviewing both PSS and SoS relevant modelling approaches. The second step is an extraction of PSS and SoS key concepts and the definition of their relationships in the PSSoS metamodel. The third step is a two-phase validation of the proposed meta-model. The first phase is confronting the meta-model to modelling experts' validation. The second phase is the instantiation of the proposed PSSoS meta-model on industrial case studies.

\subsection{Relevant literature selection criteria}

Different research steams have been focusing on PSS: Business management, Information system, and Engineering and Design (Boehm and Thomas, 2013). In this paper, we focus on Engineering and Design literature as the final objective is to propose a PSSoS design method. We search for PSS modelling approaches to extract the key concepts for PSS representation. We select papers presenting:

- Functional and structural PSS models: these models present the purpose of a PSS and describe the PSS elements able to achieve this purpose. As such, these models present the integration and the interaction between PSS elements (i.e. products, services, infrastructure, and network).

- PSS lifecycle models: These models show how to integrate independent product and service lifecycles. These models can also include a definition of the stakeholders throughout the PSS lifecycle.

- PSS design process models: These models exhibit the design process steps from defining the purpose of the PSS to defining its constituent elements. These models may also define the stakeholders taking part in the design of a PSS.

SoSs are a subject of interest in the Systems Engineering (SE) and the Enterprise Systems Engineering (ESE) domains. We select papers discussing:

- SoS architecting: these publications describe SoS constituent systems relationships.

- SoS management: These publications discuss the relationships between the SoS stakeholders.

\subsection{Qualitative interviews}

As part of the validation process, we conducted semi-structured interviews. The interviews were structured in 4 steps: a presentation of the meta-model and then discussions around 3 criteria 1) the ability of the meta-model to be understandable, 2) its coherence/ consistency with the industrial reality, 
and 3) its ability to represent industrial case studies. So far, 9 experts have been interviewed (Table 1). Most interviewees (7 out of 9) are involved in the development a mobility PSS (SoS), e.g. EV2G, connected and increasingly autonomous vehicles, etc. Based on experts' feedback, the meta-model concepts relationships have been refined. As such, the meta-model research approach is iterative.

Table 1. Interviewed experts

\begin{tabular}{|c|c|c|c|c|c|c|}
\hline \multicolumn{3}{|c|}{ Role } & \multicolumn{2}{|c|}{ Industrial Sector } \\
\hline $\begin{array}{c}\text { Systems } \\
\text { Expineering }\end{array}$ & $\begin{array}{c}\text { Model based } \\
\text { systems } \\
\text { engineering } \\
\text { expert }\end{array}$ & $\begin{array}{c}\text { Systems } \\
\text { Architect }\end{array}$ & $\begin{array}{c}\text { Project } \\
\text { manager }\end{array}$ & $\begin{array}{c}\text { Business } \\
\text { manager }\end{array}$ & $\begin{array}{c}\text { Automotive } \\
\text { industry }\end{array}$ & $\begin{array}{c}\text { Other } \\
\text { industrial } \\
\text { sectors }\end{array}$ \\
\hline 4 & 2 & 1 & 1 & 1 & 7 & 3 \\
\hline
\end{tabular}

\section{Reviewing PSS and SoS modelling approaches}

\subsection{PSS modelling approaches}

Several PSS representation models have been proposed to support PSS development and design, PSS lifecycle management, or more specifically PSS configuration and modularization.

PSS representation models systematically define the concepts of product and service. In Müller et al. (2009), products and services are core elements of a PSS. A product is defined as a technical artefact or a mechatronic system. A service is a process or a result. Hajimohammadi et al. (2017) present a PSS semantic object model where they refer to the service portfolio and product portfolio. Medini and Boucher (2019) propose an extensive generic model for PSS engineering. This model includes among others a product view and a service view where the authors distinguish core products and peripheric products. They also define service types, e.g. service for PSS operating. When a PSS representation model is used in a PSS configuration method or a PSS modularization method, the authors decompose products and services into product components and service components or modules (Fargnoli et al., 2018; Haber et al., 2018; Song et al., 2015; Song and Chan, 2015). In Welp et al. (2008), the authors rather distinguish Industrial PSS (IPS2) objects and IPS2 processes. Products and human resources are included in IPS2 objects. Service activities are included in IPS2 processes.

The purpose of the PSS is also represented in PSS modelling approaches. Schenkl et al. (2014) define a PSS layer model. The goal layer is the closest to the customer and consists of three pillars 1) PSSspecific goals, 2) Quality goals, and 3) strategic goals. Medini and Boucher (2019) define the PSS requirements view, PSS performance view, PSS demand view, and PSS offer view. The PSS requirements view includes the value of the PSS, the requirement of the end user and, the function of the PSS. The PSS performance view defines the performance dimensions and performance indicators of a PSS. The PSS demand and PSS offer view include respectively the demand of a customer and the PSS contract that will fulfil the customer's need. Müller et al. (2009) include needs and values in the customer view of the PSS development method they propose. Most authors focus on the PSS function (Hajimohammadi et al., 2017; Hara et al., 2009; Kim et al., 2011; Li et al., 2012; Sakao et al., 2009), etc. or PSS capability (Hussain et al., 2012). In (Kim et al., 2011; Welp et al., 2008), the PSS (or IPS2) function is realized by the interaction between product elements and service elements. In (Hajimohammadi et al., 2017; Li et al., 2012; Medini and Boucher, 2019), authors decompose PSS function and define functions realized by the product and functions realized by the service. In other publications, the service is considered as carrying the function and the product aspect is considered only as a resource used to satisfy PSS function (Curiazzi et al., 2016; Pezzotta et al., 2014, 2015, 2016).

PSS representation models also take into consideration PSS stakeholders. Correia et al. (Correia et al., 2017) propose a PSS ontology. The proposed PSS ontology aims at improving the communication/ collaboration among the stakeholders involved in the PSS design. As such, it includes different PSS stakeholders: product provider, service provider, PSS provider, business customer, customer, and consumer. Müller et al. (2009) consider stakeholders (providers, suppliers, customers, etc.), and contracts (Long-term commitment regulating risks, responsibilities, payment, costs, etc. business 
model description) as core elements of a PSS. Medini and Boucher (2019) consider organizational actors, their collaborations, their roles in the value network, and the activities they perform to provision an offer. Maleki et al. (2018) propose a PSS lifecycle model and a PSS business process model. In these models, the authors define the stakeholders taking part in the PSS development (customer, business partner, etc.) and their roles (service provision, service support, etc.). Tran and Park (2014) focus on the PSS design process and define the stakeholder's involvement at each design phase of the PSS. The main stakeholders considered are users and suppliers. Therefore, the PSS literature considers different stakeholders taking part in the development and operation of a PSS. However, looking at the proposed PSS lifecycles (Hepperle et al., 2010; Nguyen et al., 2014) and PSS design processes (Lim et al., 2012; Tran and Park, 2016), we notice that product and service lifecycles and design processes are often integrated (parallel). Thus, the possible managerial and operational independence of products and services is not taken into consideration.

\subsection{SoS modelling approaches}

Several researchers have been interested in the definition and characterization of SoSs. Maier (1996) defines a SoS as "a class of systems which are built from components which are large scale systems in their own right." The author also defines five characteristics enabling to distinguish a SoS from a complex system: operational independence of the elements, managerial independence of the elements, evolutionary development, emergent behaviour, and geographic distribution. Keating and Katina (2011) add interoperability, complementarity, and holism to SoS characteristics. In (Luo, 2017), the author characterises SoS innovation by expansionism, synthesis, and complementarity. According to the author, SoS innovation expands the thinking beyond the boundaries of independent systems and synthetises these systems to generate a total new functionality. This synthesis is feasible because independent systems show innate complementarity (Luo, 2017). We retain from the literature (Keating and Katina, 2011; Kotov, 1997; Luo, 2017; Maier, 1996) that a SoS is a synthesis of independent systems working together towards a common goal and producing an emergent behaviour that cannot be traced to a single system. As such, a SoS is not possible without an efficient communication and interaction among the SoS constituent systems and a collaboration between different SoS stakeholders (Maier, 1996). Therefore, significant research exists on 1) SoS architecting, i.e. defining SoS configuration/ reconfiguration and describing the relationships (or collaboration (DiMario et al., 2009)) between SoS constituent systems (Chattopadhyay et al., 2009; Dagli et al., 2013), and 2) SoS management, i.e. describing SoS stakeholders' relationships, characterizing cross-enterprise organization to support systems interoperability, and studying organization's business strategy (Carlock and Fenton, 2001).

Kinder et al. (2012) propose a framework intended to capture the dynamic nature of a SoS. The proposed framework defines a SoS through nine dimensions includes both SoS architecting and SoS management key concepts. The authors first consider the SoS constituent systems "Component Systems". Then, the authors introduce the classification, interaction, nature of the relationship, lifecycle, variability, and function dimensions. The classification dimension defines the type of the SoS whether it is directed, collaborative, virtual, or acknowledged SoS. These SoS types have been described based on the relationships among component systems (Dahmann and Baldwin, 2008; Maier, 1996). The interaction dimension details the interaction medium and the nature of the interaction between component systems, e.g. information exchange. The nature of the relationship dimension defines the category of the relationship between component systems, e.g. hierarchical or distributed control. The lifecycle dimension includes the SoS lifecycle and the component systems' timelines. The variability dimension considers the frequency of change of the SoS. The function dimension includes the functions performed by the SoS and its component systems. According to the authors, the aggregated effect of the functions gives the emergent behaviour of the SoS that fulfils the SoS purpose. Pertaining to the SoS management concepts, Kinder et al. (2012) consider the "systems owners and operations" dimension and concept of "operation/ use/ employment" dimension. These dimensions seem to relate to organisations, management, and enterprise (multi-organisational) relationships.

More specifically, Dagli et al. (2013) focus on SoS architecting and analysis. The authors propose a modelling framework for acknowledged SoSs. This modelling framework is based on the concept of 
the new capability to be achieved by the SoS. According to the authors, SoS capabilities are achieved by combining existing System capabilities and/or adding new capabilities that arise in conjunction with other Systems through systems interfaces. Other SoS research (Chattopadhyay et al., 2009; Gomes et al., 2015) also considers the notion of capability. For example, Gomes et al. (2015) define a capability as "A capability the ability of a system to provide a given functionality by performing a set of tasks" and point out the importance of capabilities in discovering and composing constituent systems within a SoS. In (Dagli et al., 2013), the authors evaluate the evolving SoS architecture capability with respect to four attributes: performance, affordability, flexibility, and robustness. Chattopadhyay et al. (2009) compare SoS alternative analysing their abilities to achieve desired levels of attribute metrics. The SoS attributes and levels of attributes (e.g. levels of performance) usually express the SoS stakeholders or decision-makers' needs (Chattopadhyay et al., 2009) and values (e.g. the value the stakeholders assign to a performance) (Ricci et al., 2014).

Enterprise SoS Engineering (Carlock and Fenton, 2001) and SoS management studies (Gorod et al., 2008; Sauser et al., 2009; Zhu and Mostafavi, 2014) are those that focus of SoS stakeholders or enterprises values and goals. Similarly to component systems, SoS stakeholders or enterprises have managerial and operational independence but together develop and operate the SoS (Rhodes et al., 2009). Mansouri et al. (2009) propose a SoS management framework for maritime transportation SoSs. The authors consider the development and operation of such a system and describe the activities performed by SoS stakeholders with regards to SoS component systems (e.g. ship manufacturing, ship maintenance, ship operation, and ship disposal). Other research (Elshenawy et al., 2018; Kilicay-Ergin et al., 2012) focuses on the operational collaborations between SoS stakeholders (and systems).

\section{A PSSoS meta-model}

\subsection{PSSoS meta-model introduction}

From previously discussed literature, we identify PSS and SoS key concepts.

A PSS is defined by its constituent elements: products, services, infrastructure, and resources (Mont, 2002). A PSS is also defined by its purpose. A PSS is intended to provide value (in use) to a customer or a user (Müller et al., 2009; Schenkl et al., 2014). PSS functions (Hajimohammadi et al., 2017; Hara et al., 2009; Kim et al., 2011; Li et al., 2012; Sakao et al., 2009), etc. or capabilities achieve the PSS purpose and provide value to the user (Hussain et al., 2012). Finally, PSS development and operation relies on a stakeholders' network. We identify different types of stakeholders: customers, providers, suppliers (Müller et al., 2009), and business partners (Maleki et al., 2018). Different approaches have been proposed to link PSS key concepts, e.g. service engineering perspective where the service carries the value and function of the PSS, systems engineering perspective (system of interest and contributing systems) (Maleki et al., 2017), and IPS2 concept modelling (Welp et al., 2008), etc.

A SoS is also defined by its constituent elements and their interactions: component systems and systems interfaces. A SoS has a purpose. The SoS achieves its purpose(s) by synthetizing SoS and component systems capabilities (Dagli et al., 2013; Luo, 2017). A capability describes the ability of the system to provide a function (Gomes et al., 2015). Finally, independent SoS stakeholders or enterprises together develop and operate the SoS (Rhodes et al., 2009). These SoS stakeholders have different roles or activities in the development and operation of the SoS. Different modelling patterns map the relationships between SoS key concepts. For instance, Ingram et al. (Ingram et al., 2014) introduce a set of five SoS architectural patterns: centralised architecture pattern, service oriented architecture pattern, publish-subscribe architecture pattern, pipes and filters architecture pattern, and blackboard architecture pattern. The patterns can be differentiated based on the nature of the relationships between SoS component systems (Kinder et al., 2012).

We aim to represent increasingly complex use-oriented and result-oriented PSS/ PSSoS (Fakhfakh et al., 2019). Hence, we adopt a service engineering perspective and integrate PSS and SoS key concepts in a four views PSSoS model (Figure 1): stakeholders view, service view, system view, and operational view. 


\section{Stakeholders view}

We define stakeholders as those who have a direct stake in the PSSoS project (Feng, 2013). We distinguish four types of stakeholders: users, SoS stakeholders, constraint stakeholders, and internal stakeholders. The users or clients are those who benefit from the final service. SoS stakeholders are independent actors or enterprises, who together collaborate and, develop and operate the SoS and the constituent systems. We define in the proposed meta-model the "collaboration" relationship between SoS stakeholders. Constraint stakeholders include, among others, law, and policy actors. Finally, internal stakeholders are actors internal to an enterprise (e.g. suppliers, engineers, etc.).

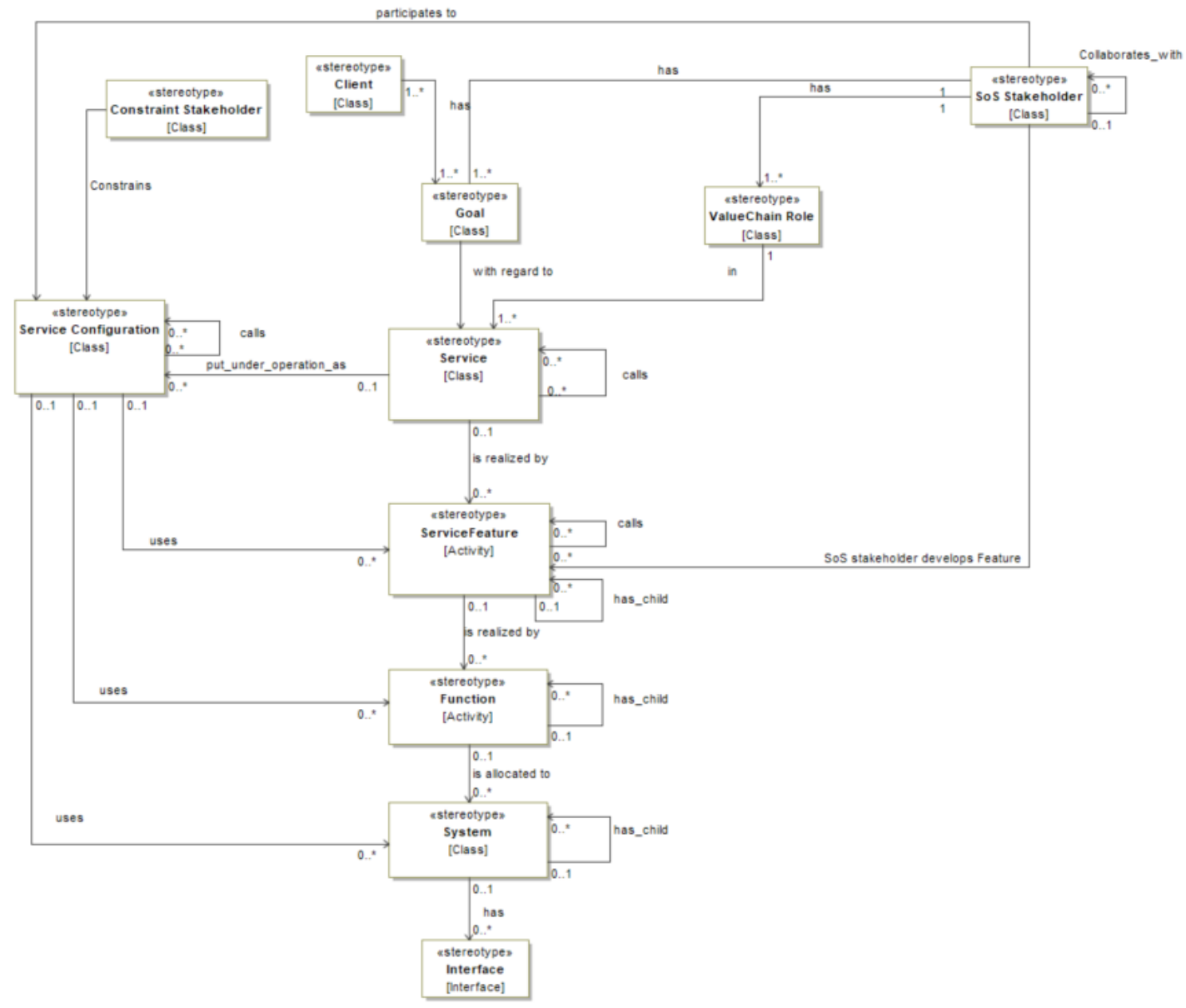

Figure 1. A PSSoS meta-model

Both users and SoS stakeholders have expectations or goals with regards to the service. Goals include quality goals (attributes) and strategic goals (specifically for the SoS stakeholders) (Schenkl et al., 2014). We further characterise SoS stakeholders by defining their value chain role and development role. The value chain role expresses the position in the value chain or the "function" the SoS stakeholder or enterprise has in the delivery of a service (Weiller and Neely, 2013). The development role specifies the capability (service feature) and, as such the system(s) the SoS stakeholder develops and/ or operates. We link a development role to a capability through the relationship "is_applied_on".

\section{Service view}

In the proposed PSSoS Meta-model, the service is what provides value to the customer and what achieves his/her goals. Thus, the service is "customer-oriented and represent main functions which are required by and sold to customers" (Yang et al., 2010). We represent services as a network. Therefore, we define the relationship "calls" between services. For example, a service that allows an electric vehicle user to identify the closest charging station needs (or "calls") car navigation services. Furthermore, a service relies on a set of capabilities or service features. We define a service feature as the type of performance that is required for the receiver's goal to be accomplished satisfactory 
(Hussain et al., 2012). We also consider a network of service features and define the relationship between service features as "calls" (or relies on, or uses). A service feature is realized by a set of functions or tasks performed by the constituent systems of the PSSoS. We model the structure of functions as a tree and define the relationship "has_child" to link functions.

\section{System view}

We consider in the proposed PSSoS meta-model, the component systems of a PSSoS. We include in the definition of a system: 1) the products (hardware and software), their functions, and behaviours, and 2) the humans and agents and their activities. Products and agents deliver the needed features for the service. The relationship "has_child" allows defining sub-systems and components of a constituent system.

The interaction between the constituent systems is fundamental since it yields the emerging behaviour of the SoS. We represent in the PSSoS meta-model the systems' interfaces through which this interaction occurs.

The proposed PSSoS meta-model aims to be a high-level description of a PSSoS. Hence, we do not consider a type of SoS (directed, collaborative, virtual or acknowledged SoS), or a type of systems relationship. Different SoS architecture patterns can then be represented (Ingram et al., 2014).

\section{Operational view}

A service can be deployed in different operational contexts (e.g. different countries with different laws and policies). Hence, depending on the operational context, a service relies on the participation of different stakeholders (SoS stakeholders, constraint stakeholders, etc.) and different component systems, and thus different PSSoS configurations. Moreover, authors (Kilicay-Ergin et al., 2012; Kinder et al., 2012) highlighted the dynamic nature of SoS and as such, PSSoS. SoS/ PSSoS architectures tend to evolve during operation (Kilicay-Ergin et al., 2012) (depending on the SoS stakeholders collaboration type, component systems relationships types, etc.). It is then important to represent these SoS or PSSoS configurations. Therefore, the PSSoS meta-model includes the concept of service configuration. A service configuration is a description of how a service is put under operation, including the participation of SoS stakeholders and the use of a set of service features, functions, and systems.

\subsection{Experts feedback analysis and an illustration of an industrial case}

In the following, we detail the experts' feedback according to the 3 criteria defined in section 2.3.

The concepts and relationships used in the PSSoS meta-model are understandable by different interviewees regardless of their roles. However, the interviewees pointed out that the use of the metamodel will depend on how familiar different actors are with model-based systems engineering (MBSE). The interviewees also confirmed the coherence of the meta-model with the industrial reality. They noted that the views the meta-model includes are holistic. Hence, the use of the meta-model can enhance collaboration between different roles (business management, service design, systems engineering) within the organization. However, they warned about the difficulty to retrieve all the information for the instantiation of the meta-model on industrial case studies. As for the ability to represent industrial cases, the PSSoS meta-model can represent a set of cases the interviewees work on. But, involving other SoS stakeholders and industrial cases from other industrial sectors is needed to confirm the ability of the meta-model to represent first mobility PSSoS and other PSSoS.

The interviews also allowed to identify potential case studies in the context of mobility services such as electric vehicle charging services and navigation services.

In this paper, we consider examples of electric vehicle (EV)-related services covered in the literature, e.g. battery leasing, battery replacement and maintenance, charging services, etc. (Chazal, 2018; Chen et al., 2016; Laurischkat and Viertelhausen, 2017; Weiller and Neely, 2013). Based on retrieved information, we illustrate the potential use of the proposed PSSoS meta-model.

We consider an EV charging service. This service facilitates the EV user's (Client's) experience when charging his/ her EV as it allows a full charge of the EV within X minutes (goal or expectation of the user). Such a service may involve the participation of several SoS stakeholders with different value chain roles, namely an OEM, an energy provider, a charging infrastructure developer and manager, and eventually a data manager. Each of these SoS stakeholders has a goal with regards to the service, for example, to generate additional revenues. The service provides service features such as finding the nearest charging station, booking a charging station, plugging and charging his/ her EV, etc. The 
design and development (development role) of the charging and plugging services features may be ensured by the OEM. Finding the nearest charging station and booking a charging station may be developed by a charging infrastructure manager. These service features are realized by a set of functions, e.g. specific functions describing the charging process. And, the functions are realized by systems: the EV, the charging station, and eventually a phone application (to book the charging station for example). The interfaces between the EV and the charging station and between the phone application and the charging station need to be designed and developed.

An EV charging service could be put in operation in two different cities. The standards and the local authorities' requirements (Constraint stakeholders) may be different and constraint the service configuration in each city. The two service configurations may also involve two different infrastructure managers which may involve a difference in the way service features are realized (functions).

The previous example illustrates the use of the proposed PSSoS meta-model. However, it is based on qualitative data gathered in the literature. The next step is to collect the industrial case studies data necessary for the instantiation of the PSSoS meta-model.

\section{Conclusion}

A PSSoS is a set of products, services, infrastructures, and networks where its constituent elements exhibit operational and managerial independence. As such, a PSSoS shows both PSS and SoS characteristics. The heterogeneity of PSS and the dynamic nature of SoS raise new design challenges. However, the literature either considers PSS design or SoS development. In this paper, we highlight the need for integrating the characteristics of a PSSoS into an appropriate PSSoS design method. And we propose a PSSoS meta-model which is the first brick towards the development of such a method. The proposed PSSoS meta-model integrates PSS and SoS key concepts identified in the PSS and SoS literature. It also consists of a stakeholder view, service view, system view, and operational view. The validation process of the proposed PSSoS meta-model has been initiated. However, the instantiation of the meta-model on industrial case studies is required. It allows for improving the meta-model. Moreover, there are several types of PSS (product-oriented, use-oriented, and result-oriented PSSs) and several types of SoS (directed, collaborative, virtual, and acknowledged SoS). The instantiation of the meta-model also allows us to verify its scope of application.

Concerning future research avenues, we will investigate the potential use of this meta-model for PSSoSs configuration management.

\section{References}

Boehm, M. and Thomas, O. (2013), “Looking beyond the rim of one's teacup: A multidisciplinary literature review of Product-Service Systems in Information Systems, Business Management, and Engineering \& Design", Journal of Cleaner Production, Elsevier Ltd, Vol. 51, pp. 245-250.

Carlock, P.G. and Fenton, R.E. (2001), "System of Systems (SoS) Enterprise Systems Engineering for Information-Intensive Organizations”, Systems Engineering, Vol. 4 No. 4, pp. 242-261.

Chattopadhyay, D., Ross, A.M. and Rhodes, D.H. (2009), "Combining Attributes for Systems of Systems in Multi-Attribute Tradespace Exploration”, Vol. 2009 No. April.

Chazal, Y. (2018), "Service Systems, System od Systems, Cyber Physical Systems: Lessons leearned from Electric Vehicles to achieve new Mobility Challenges", IEEE SOSE, available at: http://sosengineering.org/ 2018/wp-content/uploads/2014/07/Y.Chazal.pdf

Chen, T.D., Kockelman, K.M. and Hanna, J.P. (2016), "Operations of a shared, autonomous, electric vehicle fleet: Implications of vehicle \& charging infrastructure decisions", Transportation Research Part A: Policy and Practice, Elsevier Ltd, Vol. 94, pp. 243-254.

Correia, A. et al. (2017), "Ontology for colaborative development of product service systems based on basic formal ontology”, 2017 International Conference on Engineering, Technology and Innovation: Engineering, Technology and Innovation (ICE/ITMC), pp. 1173-1180.

Curiazzi, R. et al. (2016), "Process standardization to support service process assessment and re-engineering", Procedia CIRP, Elsevier B.V., Vol. 47, pp. 347-352.

Dagli, C.H. et al. (2013), “An Advanced Computational Approach to System of Systems Analysis \& Architecting Using Agent-Based Behavioral Model".

Dahmann, J.S. and Baldwin, K.J. (2008), "Understanding the Current State of US Defense Systems of Systems and the Implications for Systems Engineering”, 2008 2nd Annual IEEE Systems Conference, pp. 1-7. 
DiMario, M.J., Boardman, J.T. and Sauser, B.J. (2009), "System of systems collaborative formation", IEEE Systems Journal. available at: https://doi.org/10.1109/JSYST.2009.2029661

Elshenawy, M., Abdulhai, B. and El-Darieby, M. (2018), "Towards a service-oriented cyber-physical systems of systems for smart city mobility applications", Future Generation Computer Systems, available at: https://doi.org/10.1016/j.future.2017.09.047

Fakhfakh, S. et al. (2019), "Towards an uncertainty framework for Product Service Systems of Systems", ICED19.

Fargnoli, M., Haber, N. and Sakao, T. (2018), "PSS modularisation: a customer-driven integrated approach PSS modularisation: a customer-driven integrated approach", International Journal of Production Research, available at: https://doi.org/10.1080/00207543.2018.1481302

Feng, W. (2013), "Strategic Management for Large Engineering Projects", Engineering Project Organization Conference, p. 356.

Gomes, P. et al. (2015), "A Systematic Mapping on Discovery and Composition Mechanisms for Systems-ofSystems", 41 st Euromicro Conference on Software Engineering and Advanced Applications, IEEE, pp. 191-198.

Gorod, A., Sauser, B. and Boardman, J. (2008), "System-of-Systems Engineering Management: A Review of Modern History and a Path Forward", IEEE Systems Journal, Vol. 2 No. 4, available at: https://doi.org/10. 1109/JSYST.2008.2007163

Haber, N., Fargnoli, M. and Sakao, T. (2018), "Integrating QFD for product-service systems with the Kano model and fuzzy AHP Integrating QFD for product-service systems with the Kano model and fuzzy AHP", Total Quality Management, available at: https://doi.org/10.1080/14783363.2018.1470897

Hajimohammadi, A., Cavalcante, J. and Gzara, L. (2017), "Ontology for the PSS Lifecycle Management", Procedia CIRP, The Author(s), Vol. 64, pp. 151-156.

Hara, T., Arai, T. and Shimomura, Y. (2009), "A CAD system for service innovation : integrated representation of function, service activity, and product behaviour”, Journal of Engineering Design, Vol. 4828, available at: https://doi.org/10.1080/09544820903151715

Hein, A.M. et al. (2018), "Product Service System Design in a System of Systems Context: a Literature Survey", No. 1996, pp. 2891-2902.

Hepperle, C. et al. (2010), “An integrated lifecycle model of product-service-systems", Proceedings of the 2nd CIRP IPS2 Conference, pp. 159-166.

Hussain, R. et al. (2012), "A framework to inform PSS Conceptual Design by using system-in-use data", Computers in Industry, Elsevier B.V., Vol. 63 No. 4, pp. 319-327.

Ingram, C. et al. (2014), "Modelling Patterns for Systems of Systems Architectures", IEEE International Systems Conference Proceedings, pp. 146-153.

Keating, C.B. and Katina, P.F. (2011), "Systems of systems engineering: prospects and challenges for the emerging field", International Journal of System of Systems Engineering, available at. https://doi.org/ 10.1504/IJSSE.2011.040556

Kilicay-Ergin, N. et al. (2012), "Modeling system of systems configurations", Proceedings - 2012 7th International Conference on System of Systems Engineering, SoSE 2012, available at: https://doi.org/ 10.1109/SYSoSE.2012.6384152

Kim, Y.S., Lee, S.W. and Koh, D.C. (2011), "Representing product-service systems with product and service elements", ICED 11 - 18th International Conference on Engineering Design - Impacting Society Through Engineering Design, Vol. 4 No. August, pp. 390-399.

Kinder, A. et al. (2012), "System of Systems: 'Defining the system of interest", Proc. of the 2012 7th International Conference on Systems of Systems Engineering, No. July, pp. 463-468.

Kotov, V. (1997), "Systems of Systems as Communicating Structures".

Laurischkat, K. and Viertelhausen, A. (2017), "Business Model Gaming: A Game-Based Methodology for EMobility Business Model Innovation”, Procedia CIRP, The Author(s), Vol. 64, pp. 115-120.

Li, H. et al. (2012), "Module partition process model and method of integrated service product", Computers in Industry, Elsevier B.V., Vol. 63 No. 4, pp. 298-308.

Lim, C.H. et al. (2012), "PSS Board: A structured tool for product-service system process visualization", Journal of Cleaner Production, Elsevier Ltd, Vol. 37, pp. 42-53.

Luo, J. (2017), "System-of-systems innovation: Proactive methods for conception and strategies for implementation System-of-systems innovation : Proactive methods for", Journal of Enterprise Transformation, Taylor \& Francis, Vol. 0 No. 0, pp. 1-25.

Maier, M.W. (1996), "Architecting Principles for Systems-of-Systems", INCOSE International Symposium, Vol. 6 No. 1, pp. 565-573.

Maleki, E., Belkadi, F. and Bernard, A. (2017), "Systems Engineering as a Foundation for PSS Development Project: Motivations and Perspectives”, Procedia CIRP, Elsevier B.V., Vol. 64, pp. 205-210. 
Maleki, E., Belkadi, F. and Bernard, A. (2018), "Industrial Product-Service System modelling base on Systems Engineering: Application of sensor integration to support smart services", IFAC-PapersOnLine, Vol. 51 No. 11, pp. 1586-1591.

Mansouri, M. et al. (2009), "Maritime Transportation System of Systems management framework: a System of Systems Engineering approach", Int. J. Ocean Systems Management, Vol. 1 No. 2, pp. 200-226.

Medini, K. and Boucher, X. (2019), "Specifying a modelling language for PSS Engineering - A development method and an operational tool", Computers in Industry, Elsevier B.V, Vol. 108, pp. 89-103.

Mont, O. (2002), "Clarifying the concept of product - service system", Journal of Cleaner Production, Vol. 10, pp. 237-245.

Müller, P. et al. (2009), "PSS Layer Method - Application to Microenergy Systems", Introduction to Product/Service-System Design, Springer, London, pp. 3-30.

Nguyen, H.N. et al. (2014), "Operationalizing IPS2development process: A method for realizing IPS2developments based on Process-based project planning”, Procedia CIRP, Elsevier B.V., Vol. 16, pp. 217-222.

Pezzotta, G. et al. (2014), “Balancing product-service provider's performance and customer's value: The SErvice Engineering Methodology (SEEM)", Procedia CIRP, available at: https://doi.org/10.1016/ j.procir.2014.01.008

Pezzotta, G. et al. (2015), "A Service Engineering framework to design and assess an integrated productservice", Mechatronics, Elsevier Ltd, Vol. 31, pp. 169-179.

Pezzotta, G. et al. (2016), "Towards a methodology to engineer industrial product-service system - Evidence from power and automation industry”, CIRP Journal of Manufacturing Science and Technology, Vol. 15, pp. 19-32.

Rhodes, D.H., Ross, A.M. and Nightingale, D.J. (2009), "Constructs and Methods from the Field of Engineering Systems".

Ricci, N. et al. (2014), "Exploring Stakeholder Value Models via Interactive Visualization", Conference on Systems Engineering Research (CSER 2014), Vol. 28, pp. 294-303.

Sakao, T. et al. (2009), "Modeling design objects in CAD system for Service/Product Engineering", $C A D$ Computer Aided Design, Elsevier Ltd, Vol. 41 No. 3, pp. 197-213.

Sauser, B., Boardman, J. and Gorod, A. (2009), "System of Systems Management", System of Systems Engineering: Innovations for the 21st Century, pp. 191-217.

Schenkl, S.A., Sauer, R.M. and Mörtl, M. (2014), "A Technology-centered Framework for Product-Service Systems", Procedia CIRP, Elsevier B.V., Vol. 16, pp. 295-300.

Song, W. and Chan, F.T.S. (2015), "Multi-objective configuration optimization for product-extension service", Journal of Manufacturing Systems, The Society of Manufacturing Engineers, Vol. 37, pp. 113-125.

Song, W. et al. (2015), "Modularizing product extension services: An approach based on modified service blueprint and fuzzy graph", Computers and Industrial Engineering, Elsevier Ltd, Vol. 85, pp. 186-195.

Tran, T. and Park, J.Y. (2016), "Development of a novel set of criteria to select methodology for designing product service systems", Journal of Computational Design and Engineering, available at: https://doi.org/10.1016/j.jcde.2015.10.001

Tran, T.A. and Park, J.Y. (2014), "Development of integrated design methodology for various types of product service systems”, Journal of Computational Design and Engineering, Elsevier Masson SAS, Vol. 1 No. 1, pp. 37-47.

Weiller, C. and Neely, A. (2013), "Business Model Design in an Ecosystem Context", British Academy of Management Conference, pp. 1-21.

Welp, E.G. et al. (2008), "Modelling Approach for the Integrated Development of Industrial Product-Service Systems", In: Manufacturing Systems and Technologies for the New Frontier, Springer, London, pp. 525-530.

Yang, L., Xing, K. and Lee, S.-H. (2010), “A New Conceptual Life Cycle Model for Result-Oriented ProductService System Development", IEEE International Conference on Service Operations and Logistics, and Informatics, pp. 23-28.

Zhu, J. and Mostafavi, A. (2014), "Towards a New Paradigm for Management of Complex Engineering Projects: A System-of-Systems Framework”, International Systems Conference Proceedings. IEEE, pp. 213-219. 